\title{
The Debate on Student Evaluations of Teaching: Global Convergence Confronts Higher Education Traditions
}

Pedro Pineda, German Centre for Higher Education Research and Science Studies (DZHW), pineda@dzhw.eu

Isabel Steinhardt, International Centre for Higher Education Research (INCHER), University of Kassel, steinhardt@incher.uni-kassel.de

\begin{abstract}
Through co-occurrence analysis of 1139 documents (1964-2018) we identified trends in the discussions about the implementation of student teaching evaluation (SET). We found that: (1) Attention to SET originated in the US in the 1970s, spreading to German-speaking countries in the mid1990s and continuing in China and Latin America in the early 2000s. (2) SET is commonly viewed as a control tool deserving methodological improvement, while bias is debated in the US. We also found local trajectories: (3) Whereas in the US and Latin America SET is primarily seen as a management tool, German-speaking and Chinese authors reflect more on improving teaching. Chinese scholars consider SET a valid instrument for state control associated with artificial intelligence. Also, (4) SET is commonly used in medical education in the US and the German-speaking region and in physical education in China. We conclude that SET is discussed cross-nationally but affected by national path dependencies.
\end{abstract}

Keywords: student evaluation of teaching; teaching evaluation; quality assurance; academic discourse; bibliometric review 


\section{Introduction}

Since student teaching evaluation (SET) was first applied in the 1970s in the United States (US) (Feldman 1977; Braunstein and Benston 1973), its potential and limitations have been controversial. Advocates (Remedios and Lieberman 2008; Marsh 1984) expound on the functionality of adopting it as an accountable practice that can be applied universally. In their view, SET provides measurable goals that can be used to control or rationalize teaching through hiring, promoting, dismissal and merit pay procedures (cf. Uttl and Smibert 2017). Critics claim it is subject to bias through factors such as the attractiveness of lecturers (Wolbring 2010; Ponzo and Scoppa 2013; Rosar and Klein 2009), gender (Stark et al. 2016; Boehmer and Wood 2017; Badri et al. 2006) or ethnic background of lecturers (Anderson 2010). These authors argue that SET should primarily be used only as a feedback instrument. Despite these critiques, SET is a common procedure worldwide (Author 2 2017).

None of the research about SET, however, has adopted a historical and comparative perspective to analyze whether it is a global topic or which differences can be found in each higher education tradition. Only two cross-national studies exist (Marsh 1986; Husbands and Fosh 1993) but these engage in methodological discussions and do not approach the debates about if and why it is adopted. Therefore, exploring the discussions about how SET provides a complementary viewpoint - both analytically and geographically - to the discussions about changes about the approaches to governance in higher-education institutions. In this respect, neo-institutionalists (Ramirez et al. 2016) would expect the adoption of a technocratic approach making individual accountable at a global level - including in countries with differing higher education traditions. A hypothetical technocratic approach to rationalize teaching may be related to a view of social progress that is linked to an increasing use of technologies to capture reality.

The common adoption of procedures such as SET may evidence the cultural pressure on universities in a global world to adopt similar practices (Schofer and Meyer 2016). Since universities in the Anglo-American region rank as leaders in higher education (Meyer and Ramirez 2013), other higher education systems copy their central aspects. For example, the differentiation between excellent and non-excellent universities (Ramirez and Tiplic 2013) and the use of steering instruments, such as accreditation (Author 2 2017) or knowledge and technology transfer (Author 1 2015) originated in the US. Because SET has a long tradition in US universities, it is a procedure that universities in other higher education systems would adopt as a best practice by which to win 
legitimation. If SET is subject to isomorphism (see DiMaggio and Powell 1983), then the procedure should be found globally. However, neo-institutionalism also acknowledges that when the adoption of similar practices encounters local traditions, procedures are adapted to the respective higher education systems according to the concept of path dependence (cf. Krücken 2003).

To investigate how diffusion and path dependence interact on a global scale, we chose to analyse articles about SET in Scopus, because only a scientific database allowed us to access academic discussions on a global scale. We assume that articles in which academics discuss the structural and procedural changes in organizations and higher education systems are embedded both in mainstream and non-mainstream journals (Guzmán-Valenzuela and Gómez 2018). The main objective of this article, which provides a bird's-eye view of SET, is to identify if SET involves similar or different debates in different regions of the world. We aimed to answer the following question: Since when and how is SET discussed in different higher education traditions?

We expected to find that academic discussion of SET has diffused into different traditions of higher education and the discussions have identifiable similarities and idiosyncrasies. For comparison, we have selected countries and regions (henceforth referred to collectively as regions) that implemented SET at different times and that represent different higher education systems. Namely, the US in the 1970s, representing the Anglo-American system that first implemented SET (Feldman 1977; Braunstein and Benston 1973); German-speaking countries (Germany, Austria and Switzerland) that implemented SET in the early 1990s, representing the Humboldtian ideal's promotion of freedom of teaching and research (Rindermann 2016); China, where the implementation of SET has been discussed (Lin and Watkins 1995; Shi 2006), despite the Confucian and hierarchical character of its educational system (Marginson 2010); and countries in Latin America which have also discussed the rationalization of teaching through SET (Villavicencio 2008), despite a previous tradition of democratic governance and emphasis on sociopolitical participation (Author 12015 ).

To answer our research questions, we conducted a co-occurrence analysis of the titles, abstracts and keywords of 1139 articles in Scopus. Here, we first frame SET within the theoretical discussions on isomorphism and path dependence in higher education before we discuss the advantages and limitations of our co-occurrence analysis of articles in Scopus. Then, we present the global growth in publications since the 1970s that mention SET, including in the regions we study outside the US. Through building 
semantic maps, we prove that discussions about SET are present in regions with different higher education traditions as a tool for faculty control but emphasize different aspects and trajectories which are linked to local idiosyncrasies such as the preoccupation for bias that is salient in the US; or the emphasis on teaching improvement in German-speaking countries and China, where the validity of SET as an instrument for state control is connected with artificial intelligence. We also discuss that SET differs by academic areas depending in the region, and the discussion for medical education in the US and Germanspeaking countries contrasts to the Chinese emphasis in physical education. We end our article by proposing further comparative and historical inquiry on SET.

\section{Rationalization in Higher Education and Rationalization of Teaching}

Globalization has made education and higher education increasingly interconnected (Ramirez 2012). The interconnectedness is based on common ideas such as the belief that the application of measuring instruments to social and educational activities is linked to societal progress (Meyer and Ramirez 2013). This rationalization of universities refers to the tendency to morph into an organizational actor, to be oriented toward goals and to maximize their resources through plans and new administrative developments (Kwak et al. 2019; Krücken and Meier 2006).

The incremental use of new control mechanisms is not unique to higher education but has been occurring both globally and across sectors for about 30 years. Some authors call it a form of "post-bureaucratic" governance (Maroy 2009a, 2009b) to emphasize that these are practices based on a world of instrumental and value rationality built on Weber's thesis about the rationalization of a society. Accordingly, the bureaucratization of modern societies has continued and is related to the creation of quasi-market mechanisms and of an evaluative state. Other authors emphasize that the rationalistic trend was further pushed by new public management (NPM) approaches (Frank and Meyer 2020; Krücken and Meier 2006). This is a series of doctrines that aim to transform governmental agencies into organizations that operate under a market logic and apply procedures for management according to outcomes assessments (Frank and Meyer 2020). Under the influence of such standardizing pressures, more rationalization may be expected in different sectors, including universities, either through funding mechanisms or accreditation measures (Author 2 2017). As activities in universities become formalized and interconnected in a global society, cross-national discussions on the standardization of university activities_-including teaching — become possible. 
However, comparative higher education research has revealed not only a trend toward increasing accountability, but also the existence of regional path dependencies that offer resistance, which we can expect to find in critiques against SET. For example, in German-speaking countries the move to make teaching and learning accountable collides with the previously-held concept of Bildung as self-cultivation, which implies a tutorial relationship with a high degree of professorial autonomy and students' responsibility for their own learning process. Teaching is 'restrained' (Hopmann 2007) and is part of a broader process of lifelong personality development that is not completely compatible with the dissection of teaching and learning into periodically measured teaching improvement goals or with being held accountable by colleagues and students. Or as another example of resistance, the traditional politicized character of Latin American higher education and democratic governance known as co-gobierno (Author 1 2015) can create friction over which group is being held accountable through evaluation. SET may be limited to keep track of how much professors engage in political and social activism and is an example of a strong linkage with politics and society for their students within the third mission of universities known as extensión (outreach) besides teaching and research. As for scholars based in China, evaluations based on students' opinions may not be compatible with the social respect owed to professors and lecturers in a hierarchical system (Kember and Wong 2000) that values obedience (Marginson 2010) and ascribes social value to self-cultivation by which students can find the Way to obtain truth (dao) (Tan 2017). Although it is difficult to simultaneously study how these different higher education traditions adopt or reject the trend to make teaching accountable through SET, we can study the debates that occur in different regions by consulting scientific indexes that compile publications on a global scale.

\section{Method}

\section{Data}

To answer our research questions, we downloaded 1964 articles from Scopus (2019). We searched for the keywords student*, evaluation* and ratings in the title, keywords and abstract of an article. We used keywords in English because all reviews had a title and abstract translated into English, even when the text was in another language. We also manually discarded articles that were not unselected through our search query where SET was either not a main topic or it was addressed outside higher 
education (two independent coders had a high interrater reliability of 94\%). We downloaded separate files with publications for each of the regions that we were interested in and that broadly represent four different higher education traditions: the US, China, countries in Latin America that had articles on SET (Mexico, Brazil, Puerto Rico, Colombia, Argentina, Barbados, Bolivia, Chile and Ecuador) and countries where German is primarily spoken (Germany, Austria and Switzerland). We also tried to cover other regions, but countries such as Japan, France or the Scandinavian countries had too few publications (9, 6 and 17) to build co-occurrence maps.

\section{Analysis}

Our analysis had three steps. Fist, we built a map based on a co-occurrence analysis on the selected regions using the VOSviewer program. The co-occurrence analysis enabled us to start with a traditional quantitative content analysis through counting frequencies but with the difference that we visualized relationship between a large number of terms. Thus, the assistance of a program allows a first approach to uncover the latent structures of communication in the networks (Leydesdorff and Nerghes 2017), i.e. to trace the scientific debates in the case of our analysis.

In a second step we conducted a content analysis of the titles and abstracts with the aid of the maps that were built. Given the explorative nature of our study, we inductively did not depart from previous hypotheses that could be validated statistically. Our working hypothesis was to find similarities and differences, but we did not expect specific preestablished categories about how the clusters would organize. Our content analysis was limited to create and interpret meaningful categories from the literature (Neeundorf 2002) without the deeper interpretation power and institutional context of discourse analysis or the analysis of own stories of narrative analysis (see Cohen et al. 2018). We followed the steps of a simple content analysis identified by Flick (2018) that starts by defining units of analysis, in our case words; uses the codes to explore relevant passages, in our case titles and abstracts; formulates categories, in our research clusters; and builds new categories i.e. clusters across regions. Our computer-supported analysis differed with content analysis in using a software (VOSviewer) to assist us with word frequencies and co-occurrence maps. These served as guidelines about relationships so we could interpret large amounts of text and finally draw theoretical conclusions about isomorphic discourses or path dependencies. 
Words classified into clusters (equivalent to codes in a conventional content analysis) were the main categories for our interpretation. The final step was to give meaning to each of the word clusters through analysing how words related to each other. We further interpreted each cluster in terms of the main debates that they represent. These clusters became the second category of our analysis. Classification also followed our interpretation about how SET was approached in the literature across regions which were a third broad category of interpretation.

\section{Limitations}

This is a first explorative study that traces a line of research about how SET investigated as a paradigmatic case of a practice that represents the rationalization of teaching in a university that is building a complex system of control, represented by procedures and new organizational units. However, we acknowledge the main limitation of the study: its approach to SET through academic publications. Based on bibliometric data, we cannot answer with precision to what extent SET is being implemented. Further research in situ but with a broader comparative and historical scope may yield insights into the institutionalization of SET.

\section{The Growing Global Interest in SET}

To investigate whether SET has spread globally, the first step was to examine the growth of publications and the authors' affiliation. Almost all authors wrote about the country to which they are affiliated with only two exceptions: a comparative inquiry on incompatibilities between Dutch, French and German higher education traditions (Husbands and Fosh 1993) and a cross-national validity of SET as tested in Australia, Spain and Papua New Guinea (Marsh 1986). As Figure 1 shows, the growth in interest in SET in the US started in the mid-1970s when more than 5 publications per year can be found. SET was not an enduring topic in the literature in 1989 since when publications on the topic have grown, although with yearly fluctuations. 


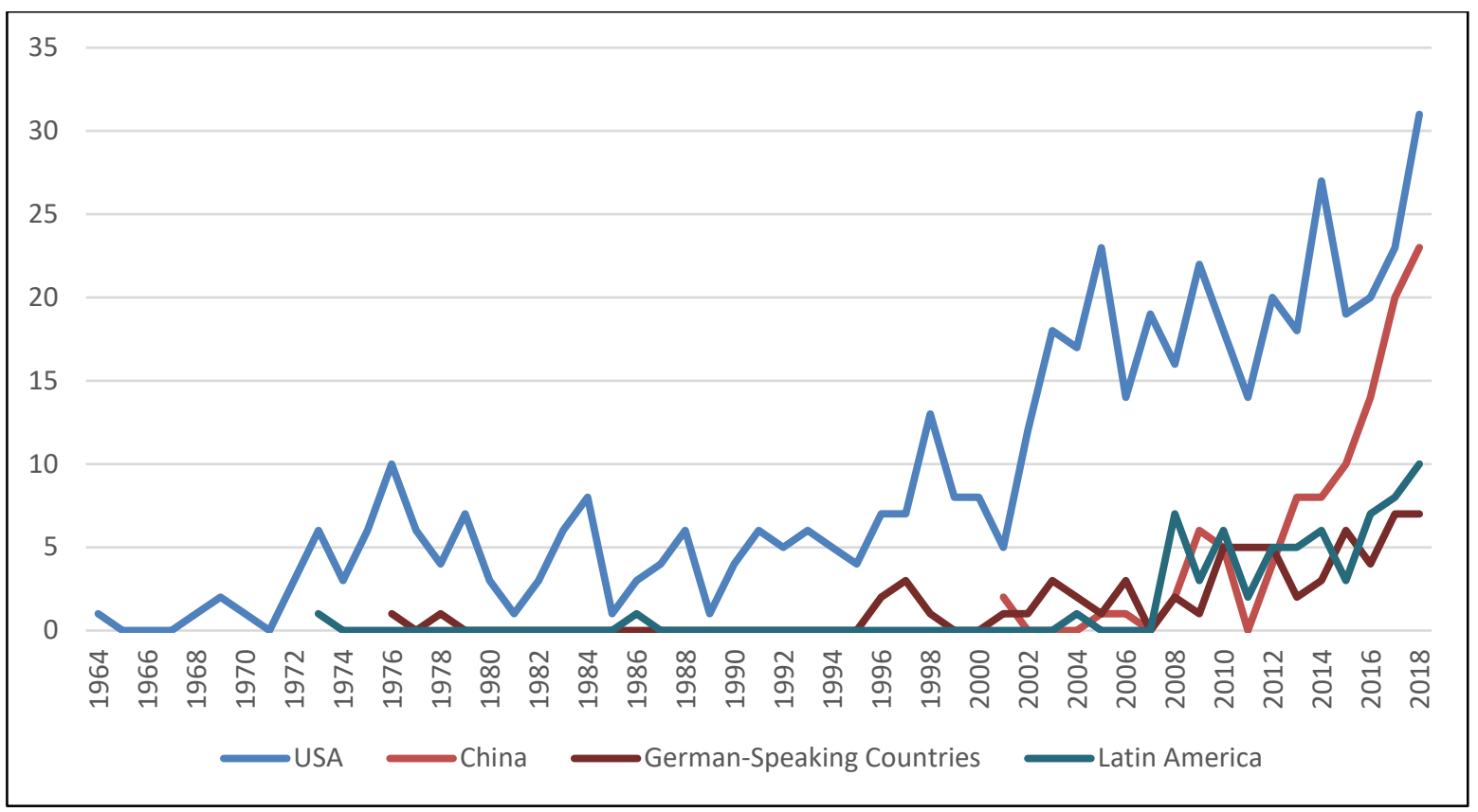

Figure 1 Articles in Scopus, 1964-2018

During its early dissemination (1964-1999), SET was a topic primarily discussed by authors in the US and Great Britain. Publications in Scopus about SET in China have increased exponentially and consistently since the 2000s. Given that scholars from the US proportionally still have over three times more papers in Scopus on topics relating to higher education (Scopus 2019), it is remarkable that the number of publications on SET in China is similar to US publications. With this rapid growth in publications, China became the third most prolific country overall, with a total of 76 publications, after the US with 495 and Australia with 100. Following behind the leading publishing countries are Germany with 55, Canada with 54, the United Kingdom with 47, Spain with 26, The Netherlands with 20 and Italy with 18. As groups, the German-speaking countries and Latin America have 66 and 65 publications, respectively. Publications on the topic in the German-speaking countries started first in 1996 and then appear consistently from 2001, earlier than in Latin America, where discussions began in 2004.

\section{Global and local debates on SET}

By using a co-occurrence analysis of publications in our regions of interest, we identified seven clusters in the discussions on SET in academic literature. In Figures 25, we labelled and coloured the different clusters according to our interpretation of their 
main topic: validity (1, red), instrument (2, purple), teaching (3, green), system (4, yellow), promotion (5, aquamarine), medical education (6, blue), and algorithm (7, grey).

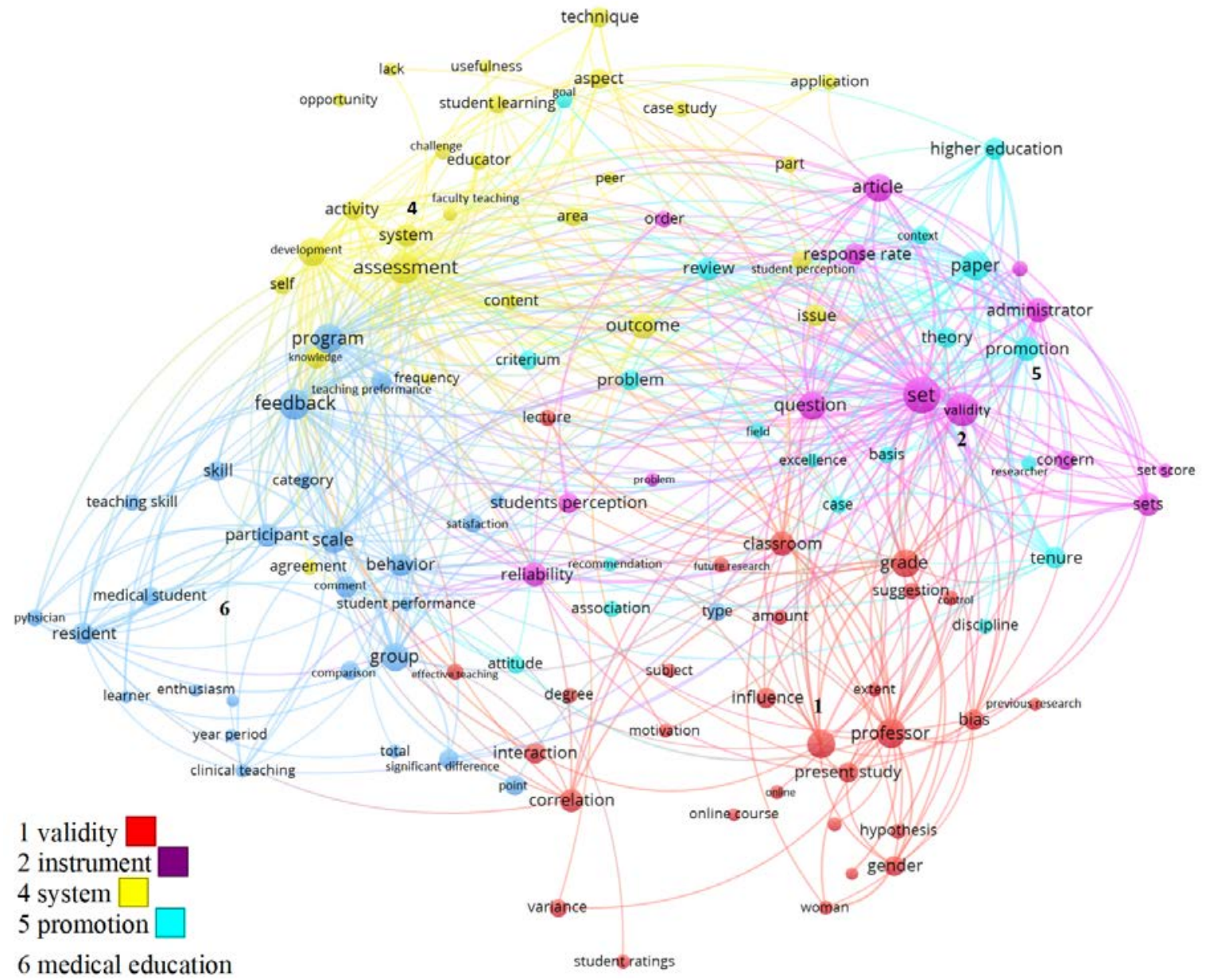

Figure 2 US-network of co-occurring words in titles and abstracts of documents on SET in Scopus, 1964-2018 


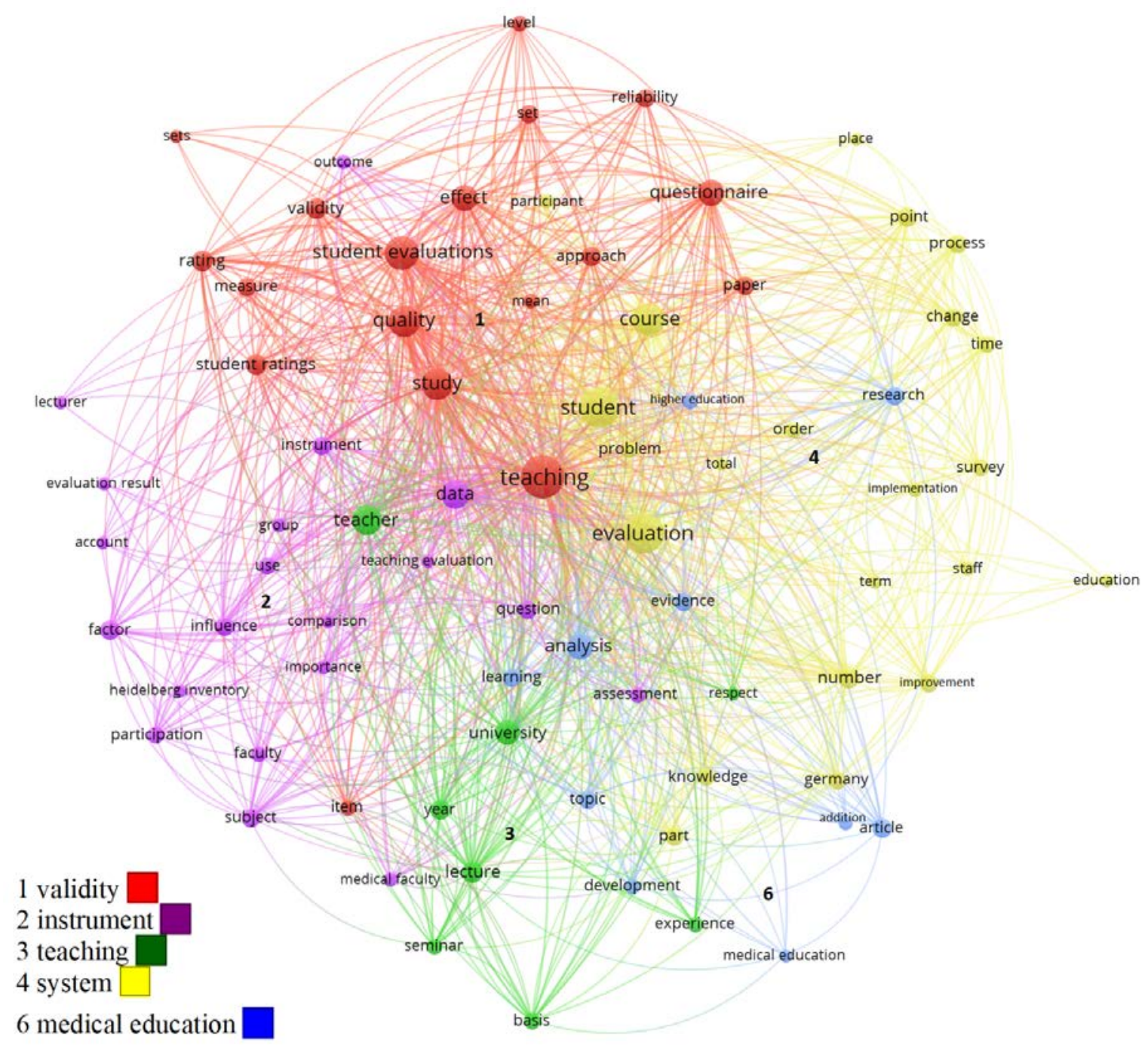

Figure 3 German network of co-occurring words in titles and abstracts of documents on SET in Scopus, 1964-2018 


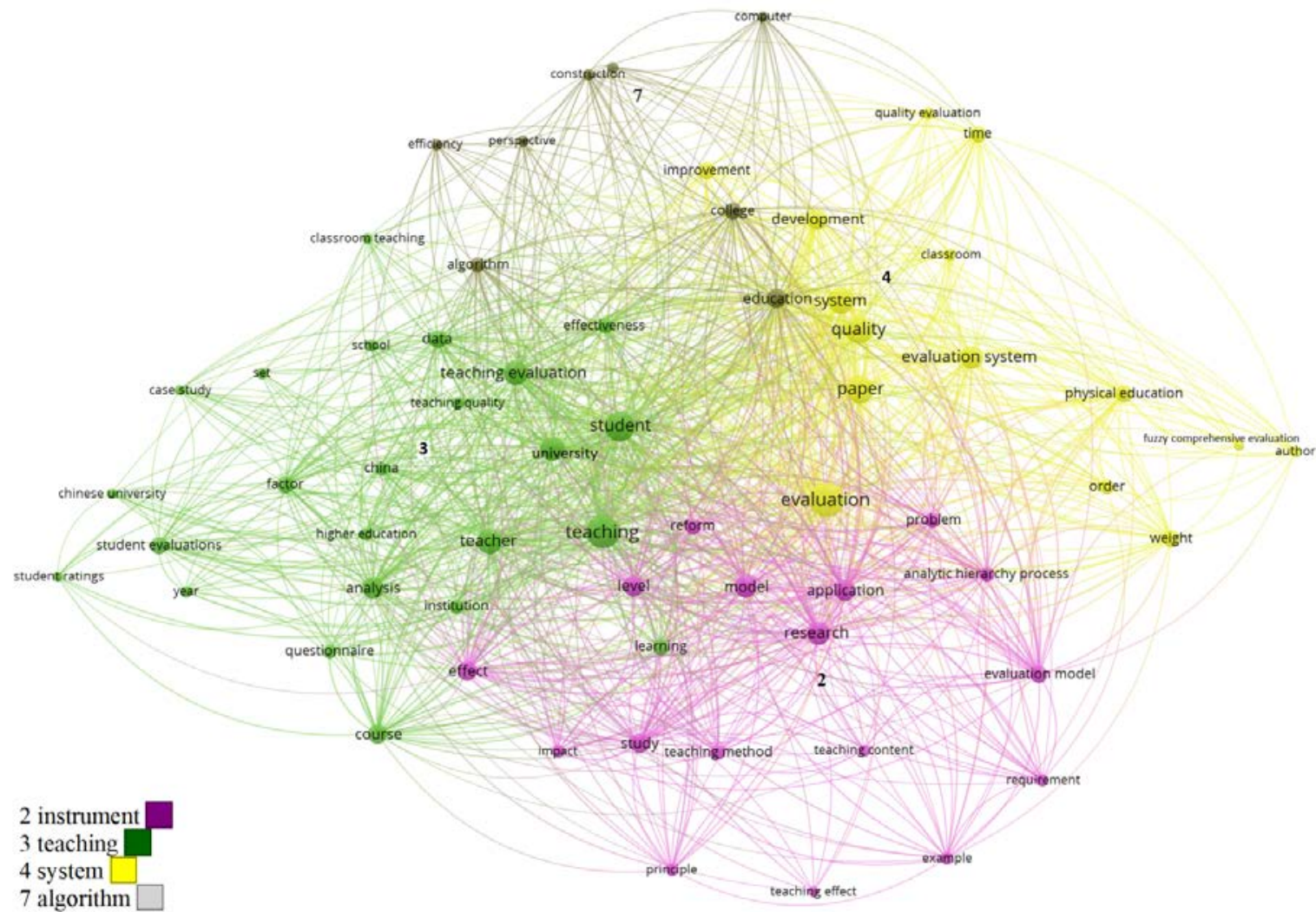

Figure 4 Chinese network of co-occurring words in titles and abstracts of documents on SET in Scopus, 1964-2018

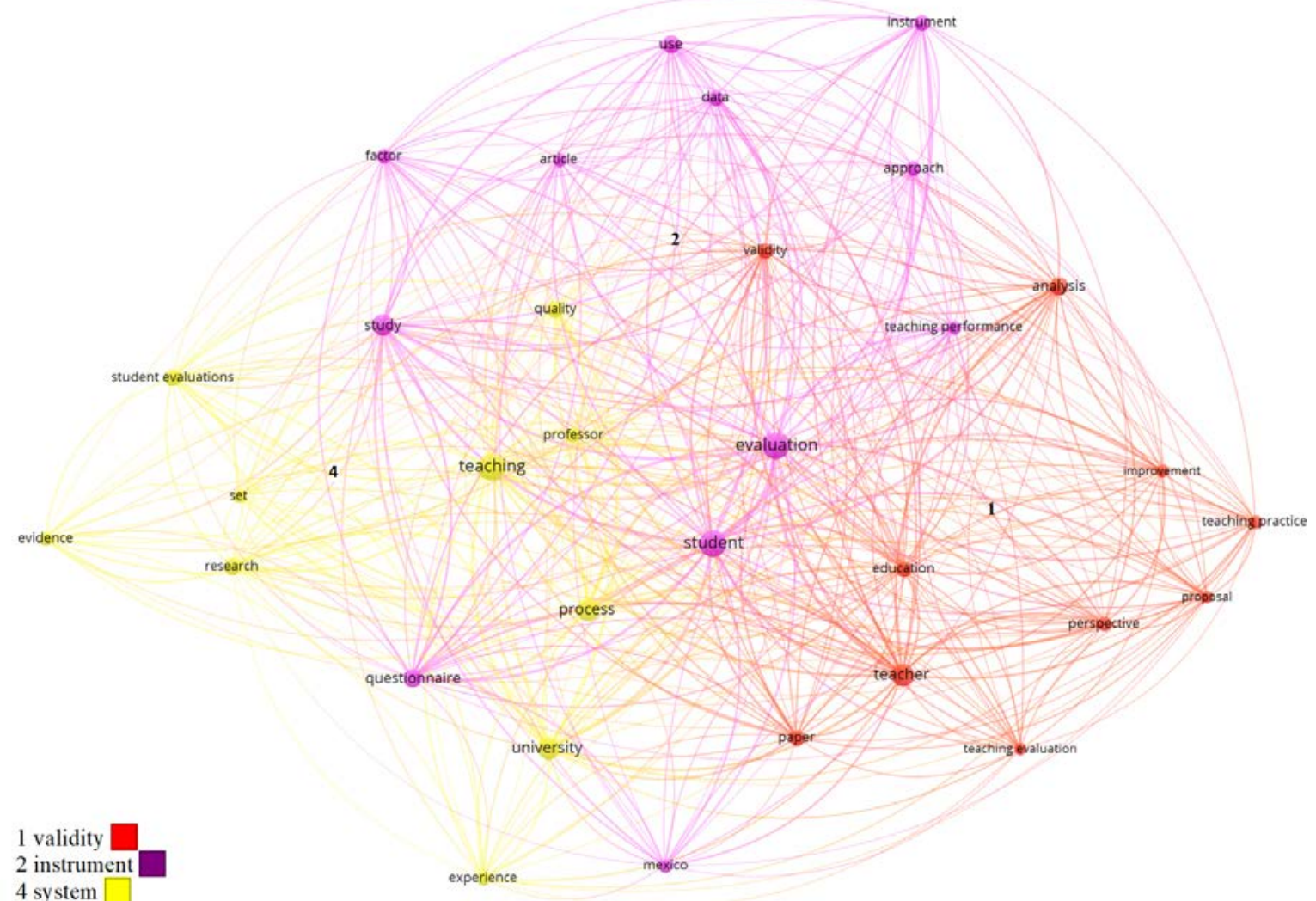

Figure 5 Latin American network of co-occurring words in titles and abstracts of documents on SET in Scopus, 1964-2018 


\section{Cluster 1: Validity}

The validity cluster (red) refers to articles concerned with the use of evaluation scores. The word 'course rating', 'student ratings' or 'grade' implies the common search for a direct measure of teaching - not about the perceptions of teaching. The main topic in the literature is the 'control' of 'variable(s)' that affect 'effective teaching' in the 'lecture' and the 'classroom'. The 'interaction' with the 'college student' is a frequent topic of study, as is the student's 'motivation'. Another main topic of discussion is the possible 'bias' or 'influence' of 'gender', with special attention to 'woman'. The relationship between SET and the 'grade' of students and 'grade inflation' is discussed as well. The 'online course' and 'online' forms of classes and evaluations, including the external web page 'ratemyprofessors.com', are also considered. Rate my Professors refers to a survey at a national level collected by a for-profit company in Menlo Park California. The predominant use of quantitative methods to evaluate or study the evaluations is also evidenced by the use of the words 'hypothesis', 'variance' in the data and analytical procedures such as 'correlation'.

A look at the differences between the regions reveals that only in the US does 'gender' appear to create a node and be central to the discussion about the validity of teaching evaluation since the 1980s (Bennett 1982) and 1990s (Amin 1994; Van Giffen 1990). References to bias against other minorities due to ethnicity appear from 2010 (e.g. Anderson 2010), but ethnicity is not central, and related words such as race or underrepresented groups do not build nodes in the co-occurrence map. A common educational problem related to bias is 'grade' and 'grade inflation' but again this is frequently discussed only in the US (e.g. Eiszler 2002).

Other discussions compare the online or paper mode of evaluation (e.g. CapaAydin 2016). The 'paper' form of implementation is also discussed in German-speaking countries, where variables that have an 'effect' in the 'reliability' of the 'rating' or 'student rating' are also included, as in research by Wolbring and Treischl (2015). The literature in China does not allow the building of a validity cluster, and we did not find the same degree of concern with validity as we found in the literature of other regions and their corresponding semantic maps. In Latin America, questions on validity are mentioned in the methodological discussion but without any particular emphasis (e.g. Garcia Garduno 2014). 


\section{Cluster 2: Instrument}

The instrument cluster is close to the validity cluster but the 'concern' is on the survey instrument, which allows for reflection on the 'reliability' and 'validity' of the 'SET score'. Literature in this semantic network employs statistical terms to discuss the 'response rate', the 'data' and the 'factor' related to teaching, which are identified through method such as 'analytic hierarchy process'. The 'order' in which 'question(s)' are given on the instrument shows again the attention paid towards the structure of the evaluation.

The instrument cluster is common to all regions and is large in each. Statisticians and experts in survey methodology or testing have applied their knowledge to build more sophisticated instruments for SET; for example, Stark et al. (2016) in the US; Samos et al. (2017) in German-speaking countries; Zuo (2012) Leong et al. (2012) in China; and Camargo-Escobar and Pardo-Adames (2008) or Laudadío (2012) in Latin America. In the German-speaking region, this cluster often discusses the validity of other instruments: the Heidelberg Inventory for the Evaluation of Teaching or the Berlin Evaluation Instrument for the Self-assessment of Student Competences (Samos et al. 2017).

\section{Cluster 3: Teaching}

Words situated in the teaching cluster (green) are expressions that stem from university didactics and pedagogy and not from statistics, administration or computer fields, as in other clusters. Authors using the words in this cluster reflect on the use of SET results to improve teaching. A differentiation between 'seminar' and 'lecture' by the 'teacher' is typical in those traditions that separate the initial and final years according to the 'experience' of the at the 'university'.

The teaching cluster is the largest cluster in China. It is relatively small in the German-speaking region and does not feature as an independent cluster in the cooccurrence analysis of articles in the US or Latin America. In the US words thematizing teaching occur with the medical cluster. The small nodes 'teaching skill' 'faculty teaching' and 'effective teaching' had a low weight that they did not create an independent cluster. Words referring to medical education were more frequent and connected, consequently we decided to label the cluster as 'medical education' instead of teaching.

We believe that these different regional approaches may be explained by previous traditions and the academic fields to which SET is linked. In the US, SET has been linked since its conception with greater emphasis on management. Also, the American tradition 
of curriculum and instruction, which started with Tyler (1949), makes a greater emphasis in learning goals and their evaluation. This approach differed to the long-standing tradition of didactics in continental Europe that does offer an established conceptual terminology on teaching (Hopmann 2007). We think that the didactics tradition could have been merged or create national discussions with the development of SET in comparison to the US where a cluster only about teaching is not built and the discussions are often in connection to medical education where terms related to teaching are merged. Conversely, the teaching cluster in German-speaking countries uses traditional language that refers to teaching and didactics in the university. El-Hage (1997) reflects on the clashes between the didactic tradition and the lack of academic reflection or sophisticated practices when SET first arrived in Germany in the early 1990s. Much of the specialized literature on didactics in specific fields are in medical education, as we will explain below.

University didactics that reflect on teaching are also absent in the Latin American countries, perhaps because of the major influence of the US on academia there in recent decades (Author 1 2015). China's Confucian heritage may have linked SET with the previous terminology used by local experts in teaching. This friction is explicitly addressed by Kember and Wong (2000), who criticize the perceived biases in Hong Kong caused by the influence of local beliefs about teaching and didactics which favour teaching and learning as imparting and memorizing knowledge, against an active teaching approach, when designing the evaluation questionnaires.

\section{Cluster 4: System}

The 'system' cluster (yellow) represents authors discussing the relationship of SET in an imagined broader administrative 'system' or 'evaluation system'. Authors use words that explain SET in the administrative process; namely, 'implementation' should promote 'improvement'. The object of the evaluation is 'staff' or 'participant'. The use of each 'application' aims for 'improvement' of teaching, and the occasional framing of SET as a specific kind of 'quality evaluation' reveals how the terminology and logic of the business sector has been transferred to controlling higher education teaching.

The discussion of SET within a broader evaluation system at the different governance levels is present in all the studied regions, beginning with the US. We think that this cluster represents the common global trend to rationalize teaching together with research and all university activities. Also, it represents the tendency to formalize faculty 
hiring, retiring, tenure decisions and compensation schemes, regardless of the local form that a teaching career takes.

The emphasis on 'physical education' acquires a particular terminology in China. SET in this area uses complex mathematical models through 'fuzzy comprehensive (evaluation)' (e.g. Zuo 2012) to establish factors related to an effective 'system' and 'effectiveness'. The system, as narrated by Chinese authors, refers to procedures of control that are not located inside the university but are part of the state communist apparatus, as a broader valuation system of physical education in colleges and universities (He 2018). Literature using this terminology intersects with the field of artificial intelligence, as discussed below.

\section{Cluster 5: Promotion}

The 'promotion' cluster (aquamarine), situated between the rating validity and system cluster in the semantic network of the US, is linked to 'tenure' decisions based on a given 'criterion'. Often the highest criterion is framed in terms of 'excellence'. The relationship between SET scores and the role of the lecturer as a 'researcher' is reflected upon. Authors using the terminology that builds this semantic map undertake analyses of the specific 'context', 'discipline' and 'field'. The use of the word 'problem' shows again that the validity of the instrument is being critically discussed. Authors often refer to a 'theory' to conceptualize the use of SET. A literature 'review' is often used to reflect on different forms of evaluation and offer a 'recommendation' for future applications.

The issues of promotion and tenure create a separate cluster in the semantic map of the US, where tenure is institutionalized both in private and public universities to protect academic freedom and incentivize the academic profession (see American Association of University Professors 1940/1978). For example, Keng (2017) identifies the fact that assistant professors grade more leniently and fail fewer students than tenured professors. Discussions on the use of SET for tenure may increase if countries (for example Germany) continue with the isomorphic adoption of the tenure track system in parallel with or to replace the automatic civil servant position attained when receiving a professorship. China and Latin America usually do not follow the tenure system but the contract type for professors is that of a civil servant in the public sector and short-term or insecure contracts in the private sector. The status of professors in China does not presuppose academic freedom (Marginson 2014), where lecturers are usually paid by hours taught and are on short-term contracts. 


\section{Cluster 6: Medical education}

'Medical education' (blue) is a discipline-specific cluster found in the semantic networks of both the US and German-speaking countries. The question raised in the literature of this cluster is how refining the 'scale' and maximizing 'student performance', 'teacher performance' and 'satisfaction' can improve the 'skill' or 'teaching skill' offered so as to improve 'medical education'. The 'behaviour' and 'enthusiasm' of the 'physician' improves the 'skill' of the 'participant', who is a 'medical student' or a 'resident'. The statistical and experimental language ('participant', 'significant difference', 'comparison') probably indicates a tendency to adapt the traditional experimental design used in medical research as a main tool for student evaluation rather than adhering to educational language from university didactics.

Discussions about the use of SET in medical education are more frequent in the US (e.g. Pratt et al. 2001). In German-speaking countries medical education is only represented by a small node within a small cluster that overlaps with the discussions about learning and is near literature on a wider evaluation system. Discussions involve specialized areas of medicine such as gynaecology (Schäfer et al. 2011) and surgery (Schürer et al. 2006). The importance of SET in medicine may occur because university didactics in medical education is often described as problematic. As noted above, the Chinese authors discuss the applications of SET in physical education but without creating a separate cluster. In Latin America, discussions on the use of SET are not associated with any particular discipline.

\section{Cluster 7: Algorithm}

The 'algorithm' cluster (grey) in the Chinese semantic map seems to be a very young topic referring to the use of artificial intelligence in the use of SET. Since 2013, computers, text mining and big data have played a prominent role in the discussion about implementing SET. Literature using the terminology that intersects in this cluster centres on the words 'computer' and 'algorithm' to promote 'efficiency' in the provision of 'education' at 'college'. This cluster was only present in China. Literature that aims to mine data on the 'sentiments of the students towards the lecture' (Leong et al. 2012) represents the belief that machine learning can be used to improve the quality of teaching. These algorithms are said to predict the quality of teaching in higher education in general and also in specific fields such as English as a foreign language (Jia and Pang 2018). The literature in China shows a radical trend of taking SET to a technocratic level that allows 
teaching to be controlled by applying computer programming to make sense of collected data.

\section{Discussion}

We offer a new perspective on understanding SET based on academic discussions in different higher education traditions. Our first contribution was identifying that, although literature about teaching evaluations by students can be found from at least 1964, it is only in the late 2000s that discussions about SET can be described as frequent on a global scale. We highlighted different points in time when scholars in each education tradition took up the discussion. Scholars actively join the discussion about SET in German-speaking countries in the mid-1990s, followed by Latin American and especially Chinese scholars in the 2000s, although evaluations had initially been imported to those regions in the mid-1990s (Lin and Watkins 1995).

Our second contribution was in showing that there are common debates about SET in places with different higher education traditions. These findings match the expectations of world society theorists (Meyer and Ramirez 2013) of a worldwide trend to apply similar instruments to make activities in universities accountable. The increasing attention of American, Chinese, German-speaking and Latin American scholars coming from different traditions may be explained by their shared belief that a monitoring system for teaching will benefit universities and national progress.

In all regions, scholars debate the use of SET as part of an apparatus by which to control the broader system using subprocesses - including teaching - that need to be quantifiable and administrated, regardless of the degree of precision that such instruments may have. In all the higher education traditions we analysed SET there is a debate on how to improve the validity of SET to make teaching accountable. Statisticians and experts in testing in all regions were discussing ways to improve the validity of the ratings as well. The debates about validity, though, were much more elaborate in the US where validity is related to concerns about gender and ethnicity to a much greater extent. References to educational problems such as grade inflation are visible and connect to using statistical language to reflect measurements of human activities, a trend that has become increasingly popular despite its reduction of complex problems to measurable aspects to which people later adapt (Espeland and Stevens 2009; Mau 2017). This language is used to legitimize or criticize SET and equivalent surveys at the national level, such as the referenced web page Rate My Professors. These deviate completely from the formative 
purpose of providing feedback but serve as a public forum to raise on shoulders or debounce those not perceived as meeting expected teaching styles of the student community.

The concerns about diversity within validity reflections replicate the presence of wider ideologies in the evaluation of teaching. Although the rhetoric on identifying and protecting minority groups can be traced to the 1920s, it has renewed after the end of the Cold War (Jiménez and Lerch 2019). The rhetoric on inclusion, though, seems to be limited mostly to gender topics. Considering the literature, women have been able to locate themselves better as empowered authors in comparison to members of other underrepresented groups (untenured lecturers, ethnic minorities, foreign academics, etc.) which could also be affected by response if validity critiques to SET hold true.

Third, we also identified debates linked to local traditions. Some debates were common to more than one region of analysis. The use of SET to reflect on the level of teaching follows a path dependence in German higher education based on the educational philosophy of Bildung that gives high autonomy to the professor and is verbalized in the field of university didactics. German-speaking countries build a much more condensed map because topics are integrated more closely around well-established debates and concepts. The current role of SET to reflect levels of teaching in China could be explained by the country's Confucian heritage that gave the professor a central role in higher education. The tradition in the US emphasizes formulating the curriculum more strongly, and this path dependency explains why reflection on teaching is not as strongly emphasized in the US as it is in German-speaking countries and China. In Latin America, the use of SET and perhaps higher education governance in general seems to be moving in the direction of the US, although the greater separation between clusters in this semantic map shows that SET is still a topic discussed by authors from different fields that are not closely connected.

We also found discussions that seem to be specific to only one of the focus regions. In the US, the country where the literature on SET emerged, debates about SET are sophisticated, involve a greater emphasis on management, validity problems and notably a lack of coupling to teaching debates. Authors place special interest on medical education in the use of SET to improve teaching. We speculate that the weight of SET in this domain of teaching could be related to the search for ways to improve an area that is commonly emphasized when it comes to improving university teaching. University didactics by professionals, who often show better specialization in their medical activities 
than in teaching, are often described as problematic for medical education (Pratt et al. 2001). Deans and scholars in these areas may therefore be more interested in adapting tools from the social sciences to improve teaching and learning and to compete for excellence. In addition, the traditional experimental design used in medicine research possibly makes medical scholars more prone to use statistics language to conceptualize the evaluation of teaching.

The critical discussion in German-speaking higher education could be related to a lower priority of teaching evaluations in decision-making. Scholars in this region reflect on the bias variables that weaken the validity of information collected by the instrument. If practice reflects such academic considerations, then it is possible that there is more caution regarding the generalized use of SET as a management instrument in Germanspeaking countries. Higher education is mostly public, there are generally no tuition fees that can be linked to the more demanding role of students as customers, and professors' autonomy may be particularly strong given that they are usually public servants (Hüther and Krücken 2014; Krücken et al. 2013). Once professors have signed a contract, the motivation to use SET may decrease. However, to attain this position, previous STEs are expected to be presented, so new temporary faculty and the younger generation of academics (junior professors and doctoral students) may be very attentive to setting and evaluating teaching goals, or at least pretend that they are. The increase in temporary faculty members and the rise of a younger generation of non-tenured academics may move the discussion in future to how SET is applied to lecturers in the university who are not civil servant professors.

In China, SET is increasingly being coupled with algorithms and big data to achieve an overall system of control. This movement runs counter to the previous Maoist higher education, which was guided by Confucian priorities of respect for professors, obedience and self-directed learning (Shi 2006; Marginson 2010; Tan 2017), that had remained isolated from a world culture promoting a different entrepreneurial model of professor accountability (Meyer et al. 2007; Meyer and Ramirez 2013). The representation of SET in Chinese literature as an unquestioned system that controls professors actually runs counter to other globalizing ideas such as student and professor empowerment and concern about discrimination and diversity (Jiménez and Lerch 2019). Increasing interest in SET shown in China occurs alongside the creation of the Shanghai Ranking of World Universities in 2003 and the official policy for "Promoting the Construction of World-Class Universities” (State Council 2015) since 2015. Publications 
about the impact of mandatory teaching evaluations tied to discussions about new methods did not exist until the previous bureaucratic and hierarchical character of universities changed under the influence of NPM doctrines introduced starting in the 1980s (L. L. Li and Jiang 2013)

The Chinese themes of social control and control of the body through physical education are explicit in the literature about SET. Physical education may be a priority because the Chinse government has aimed to improve the physical condition of the young population amid internal reports about the deterioration of their health related to a heavy study load and lack of physical activity (Liang et al. 2012). SET as an uncontested instrument to improve teaching merges easily into the national discourse on fostering the physical ability of the population. Latin American scholarship does not have any idiosyncratic approach to SET. The language used by administration to describe teaching already shows a divergent path from the previous tradition of the politicized, teachingoriented university in the Córdoba tradition, which gave professors power and limited the control exercised on them from above (Author, 2015).

\section{Conclusions}

SET was initially a concern of scholars in the US but has been increasingly debated as an artifact needing continues refinement in regions with different traditions. SET is a main topic of discussion in German and Chinese higher education where the participation of students in the evaluation of the faculty is not the historical tradition. Furthermore, unique debates about how to institutionalize SET as a mechanism of control allows us to theorize about current local agendas that represent contemporary path dependencies. The managerial language in the US and Latin America coincides with the enduring influence of the entrepreneurial model in teaching and its regional influence in the Americas. German-speaking and Chinese authors reflect longstanding discussions in the improvement of teaching that now must deal with the arrival of SET. The increasing attention from China, a latecomer now sharing publication numbers with the US, is as notable as is the description in literature of SET as an instrument for state control that can be improved through artificial intelligence. We also did not anticipate the special attention that scholars in medical education and sport education put to SET, especially in the US and China, respectively.

Interest in this form of evaluation does not occur in a vacuum but in relation to changes in the broader process of the rationalization of universities. The first discussions 
about SET at the beginning of the 1970s occur in the unregulated environment of the US. The first discussions about evaluating teaching were connected to statements about increasing accountability for entrepreneurs, religious groups, industry, and, of course, empowered students paying increasingly high tuition fees (see Cowen 1996). After the end of the Cold War, the US government intensified this relationship to universities, tuition fees further increased and discussions about accounting systems such as SET became more accepted (Frank and Meyer 2020). These changes were not inevitable but the result of globalizing cultural ideologies and a terminology used as cultural artifacts to rationalize activities within universities, including teaching. Only after NPM influenced traditional state bureaucracy did scholars engage with discourses about how to rationalize teaching. This occurred in German-speaking Europe until the mid-1990s, in China in the 1980s and in Latin America in the 1990s (L. Li et al. 2013; Schimank 2005; Ospina et al. 2004). This is the ideological context in which SET start to be debated as normal and necessary, and only occasionally educationally problematic.

To conclude, the global interest in SET epitomizes the rationalization of teaching in the rationalized university. The debates about SET are a global trend which we observe through discussions about its implementation with chronological and geographical differences. We found that parallel developments do exist in academic discussions about implementing SET in higher education traditions which were historically distant from the American, entrepreneurial university where the first debates appear. This is the case for literature on higher education in China, the German-speaking countries, and Latin America. Therefore, it is possible to conclude that debates about SET are indicative of rationalization of higher education and rationalization of teaching that is occurring globally.

Further comparative research may locate SET historically and in different higher education traditions. We acknowledged that an advantage of our study was providing a global picture but a limitation of our analysis is that it does not allow us to compare practices in the academic discourses we studied. A research program comparing evaluation practices would be able to position SET as a representative topic that allows for theorization on global shifts in higher-education governance. If there are such convergent trends to rationalize teaching - and we found evidence to suggest it is - then the teaching by professors previously influenced by Humboldtian, Confucian or LatinAmerican traditions may now also be viewed as controlled by instruments with the 
required validity within a system that corresponds to Weber's 'iron cage' of collective rationality (see DiMaggio and Powell 1983).

Still, it would be interesting to further explore differences found during the course of this research. The growing discussion on the discriminatory effects of SET suggests that a reformist spirit is present in the US. This trend could gain momentum because it is supported by the cultural influence of an international agenda that favours equal rights for individual groups such as gender or ethnic groups (cf. Ramirez et al. 2016). Future bibliometric mapping analyses could follow if these discussions also globalize and have an influence in changing or even dismantling quantitative, high stake versions of SET. Also, in German-speaking countries and China, where professors historically had much more power in their relations with students, it would be interesting to further explore if this hierarchical relationship changes in line with the convergent trends towards implementing SET and a tenure-track career structure. Further studies could explore if countries that do not reflect democratic values encourage student voices in SET while repressing citizen participation. Studying the propensity to use SET by countries such as Italy, Sweden and France could be particularly enlightening, given that Clark’s (1986) comparative analysis in the 1980s described these countries as comparatively impermeable to making the professor accountable. It could also be of interest to verify whether Japan's comparatively low number of publications in our analysis can be explained by publishing patterns or is related to resistance to adopting SET. The use of SET in private and public sectors and in the tenure, tenure-track and adjunct positions (or their equivalent) also needs to be investigated. Furthermore, an organizational perspective could research which office and positions are in charge of SET.

\section{Funding Sources}

This work was supported by [details removed for peer review].

\section{Acknowledgements}

We would like to thank [details removed for peer review] for comments that help us preparing the proposal and final version of this article.

\section{Declaration of interest statement}

No potential competing interest was reported by the authors. 


\section{References}

American Association of University Professors (1940/1978). 1940 Statement of Principles on Academic Freedom and Tenure. AAUP Bulletin, 64(2), 108-112.

Amin, M. E. (1994). Gender as a Discriminating Factor in the Evaluation of Teaching. [Article]. Assessment \& Evaluation in Higher Education, 19(2), 135-143, doi:10.1080/0260293940190206.

Anderson, K. J. (2010). Students' stereotypes of professors: an exploration of the double violations of ethnicity and gender. Social Psychology of Education, 13(4), 459472, doi:10.1007/s11218-010-9121-3.

Author 1 (2015). [details removed for peer review].

Author 2 (2017). [details removed for peer review].

Badri, M. A., Abdulla, M., Kamali, M. A., \& Dodeen, H. (2006). Identifying potential biasing variables in student evaluation of teaching in a newly accredited business program in the UAE. [Article]. International Journal of Educational Management, 20(1), 43-59, doi:10.1108/09513540610639585.

Bennett, S. K. (1982). Student perceptions of and expectations for male and female instructors: Evidence relating to the question of gender bias in teaching evaluation. Journal of Educational Psychology, 74(2), 170-179, doi:10.1037/0022-0663.74.2.170.

Boehmer, D. M., \& Wood, W. C. (2017). Student vs. faculty perspectives on quality instruction: Gender bias, "hotness," and "easiness" in evaluating teaching. [Article]. Journal of Education for Business, 92(4), 173-178, doi:10.1080/08832323.2017.1313189.

Braunstein, D. N., \& Benston, G. J. (1973). Student and department chairman views of the performance of university professors. [Article]. Journal of Applied Psychology, 58(2), 244-249, doi:10.1037/h0035630.

Camargo-Escobar, I. M., \& Pardo-Adames, C. (2008). Teaching skills in undergraduate level teachers: Design and validation of an evaluation instrument. [Article]. Universitas Psychologica, 7(2), 441-455.

Capa-Aydin, Y. (2016). Student evaluation of instruction: comparison between in-class and online methods. [Article]. Assessment and Evaluation in Higher Education, 41(1), 112-126, doi:10.1080/02602938.2014.987106.

Clark, B. R. (1986). The higher education system: academic organization in crossnational perspective. Berkeley: University of California Press.

Cohen, L., Lawrence, M., \& Morrison, K. (2018). Research methods in Education. London, New York: Routledge.

Cowen, R. (1996). Performativity, Post-modernity and the University. Comparative Education, 32(2), 245-258, doi:10.1080/03050069628876. 
DiMaggio, P. J., \& Powell, W. W. (1983). The Iron Cage Revisited: Institutional Isomorphism and Collective Rationality in Organizational Fields. American Sociological Review, 48(2), doi:10.2307/2095101.

Eiszler, C. F. (2002). College students' evaluations of teaching and grade inflation. [Article]. Research in Higher Education, 43(4), 483-501, doi:10.1023/A:1015579817194.

El-Hage, N. (1997). Evaluation of Higher Education in Germany. Quality in Higher Education, 3(3), 225-233, doi:10.1080/1353832970030303.

Espeland, W. N., \& Stevens, M. L. (2009). A Sociology of Quantification. European Journal of Sociology, 49(03), doi:10.1017/s0003975609000150.

Feldman, K. A. (1977). Consistency and variability among college students in rating their teachers and courses: A review and analysis. Research in Higher Education, 6(3), 223-274, doi:10.1007/bf00991288.

Flick, U. (2018). An Introduction to Qualitative Research. Los Angeles: SAGE.

Frank, D. J., \& Meyer, J. W. (2020). The University and the Global Knowledge Society. Princeton: Princeton University Press.

Garcia Garduno, J. M. E. (2014). ¿Para qué sirve la evaluación de la docencia? Un estudio exploratorio de las creencias de los estudiantes universitarios. Education Policy Analysis Archives, 22(15), doi:10.14507/epaa.v22n15.2014.

Guzmán-Valenzuela, C., \& Gómez, C. (2018). Advancing a knowledge ecology: changing patterns of higher education studies in Latin America. Higher Education, doi:10.1007/s10734-018-0264-z.

He, Y. (2018). Construction Of Physical Education Evaluation System In Chinese Colleges And Universities. Journal of Web Engineering, 17(12), 101-107, doi:10.26802/jaots.2018.09240.

Hopmann, S. (2007). Restrained teaching: the common core of Didaktik. European Educational Research Journal, 6(2), 109-124, doi:10.2304/eerj.2007.6.2.109.

Husbands, C. T., \& Fosh, P. (1993). Students' Evaluation of Teaching in Higher Education: Experiences from four European countries and some implications of the practice. [Article]. Assessment \& Evaluation in Higher Education, 18(2), 95114, doi:10.1080/0260293930180202.

Hüther, O., \& Krücken, G. (2014). The rise and fall of student fees in a federal higher education system: The case of Germany. In C. Depuy, \& H. Ertl (Eds.), Students, Markets and Social Justice: higher education fee and student support policies in Western Europe and beyond (pp. 85-110). Oxford: Symposium Books.

Jia, S., \& Pang, Y. (2018). Teaching Quality Evaluation and Scheme Prediction Model Based on Improved Decision Tree Algorithm. International Journal of Emerging Technologies in Learning (iJET), 13(10), doi:10.3991/ijet.v13i10.9460. 
Jiménez, J. D., \& Lerch, J. C. (2019). Waves of Diversity: Depictions of Marginalized Groups and Their Rights in Social Science Textbooks, 1900-2013. Comparative Education Review, 000-000, doi:10.1086/702606.

Kember, D., \& Wong, A. (2000). Implications for evaluation from a study of students' perceptions of good and poor teaching. [Article]. Higher Education, 40(1), 69-97, doi:10.1023/a:1004068500314.

Keng, S.-H. (2017). Tenure system and its impact on grading leniency, teaching effectiveness and student effort. Empirical Economics, 55(3), 1207-1227, doi:10.1007/s00181-017-1313-7.

Krücken, G. (2003). Learning the 'new, new thing': on the role of path dependency. Higher Education, 46(3), 315-339.

Krücken, G., Blümel, A., \& Kloke, K. (2013). The Managerial Turn in Higher Education? On the Interplay of Organizational and Occupational Change in German Academia. Minerva, 51(4), 417-442, doi:10.1007/s11024-013-9240-z.

Krücken, G., \& Meier, F. (2006). Turning the University Into an Organizational Actor. In Globalization and Orgnization: World Society and Organizational Change (pp. 241-258). New York: Oxford University Press.

Kwak, N., Gavrila, G., \& Ramirez, F. O. (2019). Enacting diversity in American higher ducation: reputation and professionalization. In T. Christensen, Å. Gornitzka, \& F. O. Ramirez (Eds.), Universities as Agencies (pp. 209-228). New York: Universities as Agencies: Reputation and Professionalization.

Laudadío, J. (2012). Evaluation of teaching styles at college: Preliminary study of the psychometric properties of the questionnaire on the teaching orientation of the university professor. [Article]. Interdisciplinaria, 29(1), 79-93.

Leong, C. K., Lee, Y. H., \& Mak, W. K. (2012). Mining sentiments in SMS texts for teaching evaluation. Expert Systems with Applications, 39(3), 2584-2589, doi:10.1016/j.eswa.2011.08.113.

Leydesdorff, L., \& Nerghes, A. (2017). Co-word maps and topic modeling: A comparison using small and medium-sized corpora $(\mathrm{N}<1,000)$. Journal of the Association for Information Science and Technology, 68(4), 1024-1035, doi:10.1002/asi.23740.

Li, L., Lai, M., \& Lo, L. N. K. (2013). Academic work within a mode of mixed governance: Perspectives of university professors in the research context of western China. [Article]. Asia Pacific Education Review, 14(3), 307-314, doi:10.1007/s12564-013-9260-2.

Li, L. L., \& Jiang, Z. G. (2013). A Professional Learning of the Implementation of Individualized Education in Cultivating Mode of Innovative Talents - A Case Study of Individualized Education in Hebei University of Science and Technology. In X. M. Huang (Ed.), Proceedings of the 2013 the International Conference on Education Technology and Information System (Vol. 65, pp. 601604, Advances in Intelligent Systems Research). Paris: Atlantis Press. 
Liang, G., Housner, L., Walls, R., \& Yan, Z. (2012). Failure and revival: physical education and youth sport in China. Asia Pacific Journal of Sport and Social Science, 1(1), 48-59, doi:10.1080/21640629.2012.681886.

Lin, W. Y., \& Watkins, D. (1995). Students' evaluations of university teaching: A china perspective. [Article]. Higher Education Research \& Development, 14(1), 61-74, doi:10.1080/0729436950140106.

Marginson, S. (2010). Higher education in East Asia and Singapore: rise of the Confucian Model. Higher Education, 61(5), 587-611, doi:10.1007/s10734-010-9384-9.

Marginson, S. (2014). Academic Freedom: A Global Comparative Approach. Frontiers of Education in China, 9(1), 24-41, doi:10.3868/s110-003-014-0003-x.

Maroy, C. (2009a). Convergences and hybridization of educational policies around 'postbureaucratic' models of regulation. Compare, 39(1), 71-84.

Maroy, C. (2009b). Introduction to the sub-issue 'New modes of regulation of education systems'. Compare, 67-70.

Marsh, H. W. (1984). Students' evaluations of university teaching: Dimensionality, reliability, validity, potential baises, and utility. Journal of Educational Psychology, 76(5), 707-754, doi:10.1037/0022-0663.76.5.707.

Marsh, H. W. (1986). Applicability paradigm: Students' evaluations of teaching effectiveness in different countries. Journal of Educational Psychology, 78(6), 465-473, doi:10.1037/0022-0663.78.6.465.

Mau, S. (2017). Das metrische Wir - Über die Quantifizierung des Sozialen. Berlin: Suhrkamp.

Meyer, J. W., \& Ramirez, F. O. (2013). Universalizing the university in a world society. In Institutionalization of World Class University in Global Competition (pp. 257274). Dordrecht: Springer.

Meyer, J. W., Ramirez, F. O., Frank, D. J., \& Schofer, E. (2007). Higher education as an institution. In P. J. Gumport (Ed.), Sociology of Higher Education: Contributions and Their Contexts (pp. 187-221). Baltimore: Johns Hopkings University Press.

Neeundorf (2002). The Content Analysis Guidebook. Thousand Oaks: Sage.

Ospina, S., Cunill Grau, N., \& Zaltsman, A. (2004). Performance evaluation, public management improvement and democratic accountability. Public Management Review, 6(2), 229-251, doi:10.1080/1471903042000189119.

Ponzo, M., \& Scoppa, V. (2013). Professors' beauty, ability, and teaching evaluations in italy. [Article]. B.E. Journal of Economic Analysis and Policy, 13(2), 811-835, doi:10.1515/bejeap-2012-0041.

Pratt, D. D., Arseneau, R., \& Collins, J. B. (2001). Reconsidering "good teaching" across the continuum of medical education. [Review]. The Journal of continuing education in the health professions, 21(2), 70-81, doi:10.1002/chp.1340210203. 
Ramirez, F. O. (2012, The world society perspective: concepts, assumptions, and strategies. Comparative Education, pp. 423-439.

Ramirez, F. O., Meyer, J. W., \& Lerch, J. (2016). World society and the globalization of educational policy. In K. Mundy, A. Green, L. Bob, \& A. Verger (Eds.), The Handbook of Global Education Policy (pp. 43-63). Malden: John Wiley \& Sons.

Ramirez, F. O., \& Tiplic, D. (2013). In pursuit of excellence? Discursive patterns in European higher education research. Higher Education, 67(4), 439-455, doi:10.1007/s10734-013-9681-1.

Remedios, R., \& Lieberman, D. A. (2008). I liked your course because you taught me well: the influence of grades, workload, expectations and goals on students' evaluations of teaching. British Educational Research Journal, 34(1), 91-115, doi:10.1080/01411920701492043.

Rindermann, H. (2016). Lehrveranstaltungsevaluation an Hochschulen. In D. Großmann, \& T. Wolbring (Eds.), Evaluation von Studium und Lehre: Grundlagen, methodische Herausforderungen und Löungsansätze (pp. 227-263): Spinger.

Rosar, U., \& Klein, M. (2009). Mein(schöner)Prof.de. The physical attractiveness of academic staff and its influence on evaluations by students. [Article]. Kolner Zeitschrift fur Soziologie und Sozialpsychologie, 61(4), 621-645, doi:10.1007/s11577-009-0086-1.

Samos, F. A., Heise, M., Fuchs, S., Mittmann, S., Bauer, A., \& Klement, A. (2017). Pilot phase evaluation of the elective general practice class: Results of student surveys of the first two years. [Article]. GMS Journal for Medical Education, 34(1), doi:10.3205/zma001081.

Schäfer, J., Beckmann, M., \& Frobenius, W. (2011). Deutliche Verbesserungen in der Ausbildung PJ-Studierender. Geburtshilfe und Frauenheilkunde, 71(11), 956966, doi:10.1055/s-0031-1280288.

Schimank, U. (2005). 'New Public Management' and the Academic Profession: Reflections on the German Situation. Minerva, 43(4), 361-376, doi:10.1007/s11024-005-2472-9.

Schofer, E., \& Meyer, J. W. (2016). The Worldwide Expansion of Higher Education in the Twentieth Century. American Sociological Review, 70(6), 898-920, doi:10.1177/000312240507000602.

Schürer, S., Schellberg, D., Schmidt, J., Kallinowski, F., Mehrabi, A., Herfarth, C., et al. (2006). Evaluation of traditional German undergraduate surgical training. An analysis at Heidelberg University. [Article]. Chirurg, 77(4), 352-359, doi:10.1007/s00104-005-1123-x.

Scopus (2019). Document Search. https://www-scopus-com. Accessed June 242019.

Shi, L. (2006). The Successors to Confucianism or a New Generation? A Questionnaire Study on Chinese Students' Culture of Learning English. Language, Culture and Curriculum, 19(1), 122-147, doi:10.1080/07908310608668758. 
Stark, P., Ottoboni, K., \& Boring, A. (2016). Student Evaluations of Teaching (Mostly) Do Not Measure Teaching Effectiveness. ScienceOpen Research, doi:10.14293/S2199-1006.1.SOR-EDU.AETBZC.v1.

State Council (2015). Notice of the State Council on Printing and Distributing the Overall Plan for Promoting the Construction of World-Class Universities and First-Class Disciplines,. 11/05/content_10269.htm. http://www.gov.cn/zhengce/content/2015-

Tan, C. (2017). A Confucian perspective of self-cultivation in learning: Its implications for self-directed learning. Journal of Adult and Continuing Education, 23(2), 250262, doi:10.1177/1477971417721719.

Tyler, R. (1949). Basic Principles of Curriculum and Instruction. Chicago: University of Chicago Press.

Uttl, B., \& Smibert, D. (2017). Student evaluations of teaching: Teaching quantitative courses can be hazardous to one's career. [Article]. PeerJ, 2017(5), doi:10.7717/peerj.3299.

Van Giffen, K. (1990). Influence of professor gender and perceived use of humor on course evaluations. Humor - International Journal of Humor Research, 3(1), doi:10.1515/humr.1990.3.1.65.

Villavicencio, J. E. (2008). Teachers performance evaluation: the experience of the Dentist Academic Program of the Universidad del Valle. [Article]. Colombia Medica, 39(1), 57-63.

Wolbring, T. (2010). Attraktivität, Geschlecht und Lehrveranstaltungsevaluation: Eine Replikationsstudie zu den Befunden von Hamermesh und Parker (2005) und Klein und Rosar (2006) mit Hilfe von Individualdaten. Zeitschrift für Evaluation, 9(1), 29-48, doi:10.1007/s11162-017-9452-4.

Wolbring, T., \& Treischl, E. (2015). Selection Bias in Students' Evaluation of Teaching. Research in Higher Education, 57(1), 51-71, doi:10.1007/s11162-015-9378-7.

Zuo, N. (2012). Study on Evaluation of Student Practical Teaching Ability in Physical Education with Intuitionistic Fuzzy Information. Journal of Convergence Information Technology, 7(18), 223-229, doi:10.4156/jcit.vol7.issue18.27. 